\title{
Decomposition of Peroxides in Polystyrene and Some Solid Arenes
}

\author{
Hiroshi Minato, ${ }^{*}$ Chieko Kato, and Ikuko MoRI \\ Department of Chemistry, International Christian University, \\ Osawa, Mitaka, Tokyo, Japan.
}

(Received July 12, 1975)

\begin{abstract}
In order to cinnamoyloxylate polystyrene, cinnamoyl peroxide was decomposed in polystyrene film. The rates and products of the decomposition were determined. Products were cinnamoyloxypolystyrene, cinnamic acid, and a mixture of cinnamic acid esters (mainly styryl cinnamate). It was found that $0.11 \mathrm{~mol}$ cinnamoyloxy group per mol of cinnamoyl peroxide was attached to the polystyrene nuclei. The results were compared with those for the decomposition of benzoyl peroxide in polystyrene. The rates of decomposition of peroxides in some solid aromatics were then studied. The decompositions in solid biphenyl were slow, but those in phenanthrene were very fast. The results were interpreted in terms of the ionization potentials of the aromatics.
\end{abstract}

KEY WORDS Cinnamoyl Peroxide/Benzoyl Peroxide / Polystyrene / Decomposition in Solids /

Cinnamoyl groups are light-sensitive, and the introduction of $\mathrm{Ph}-\mathrm{CH}=\mathrm{CH}-\mathrm{COO}-$ groups into polystyrene is of interest since the polymers thus formed are expected to cross-link upon irradiation with light. A convenient method for the introduction of cinnamoyloxy groups into polystyrene appeared to be the decomposition of cinnamoyl peroxide in polystyrene. Such an investigation has been carried out, and the results are described in this paper. Decompositions of benzoyl peroxide in polystyrene, phenanthrene and biphenyl have also been investigated, and the results are compared.

\section{EXPERIMENTAL}

\section{Materials}

Polystyrene was prepared by the emulsion polymerization of styrene at $10^{\circ} \mathrm{C}$ with a redox system of polyamine-iron-hydroperoxide. ${ }^{1}$ Viscosity-average molecular weight was 126,000 .

Cinnamoyl peroxide was prepared by the method described by Sana, Nandi, and Palit. ${ }^{2}$

Decomposition of Cinnamoyl Peroxide in Polystyrene

Polystyrene and cinnamoyl peroxide were dis-

* To whom correspondence should be addressed at Department of Chemistry, Tokyo Metropolitan University, Setagaya-ku, Tokyo 158, Japan. solved in benzene, and the polystyrene solution was evaporated on a glass plate of limited area. The polystyrene film obtained was heated in an oven at $80^{\circ} \mathrm{C}$. The decomposition of peroxide was followed by the decrease of the carbonyl absorption at $1785 \mathrm{~cm}^{-1}$. The infrared spectra of the polystyrene film after complete decomposition of peroxide had weak absorptions at 1730 and $1690 \mathrm{~cm}^{-1}$. Although this infrared method cannot be regarded as very accurate, it is a convenient method. When $[\mathrm{P}] /\left[\mathrm{P}_{0}\right]$ was plotted against time $\left([\mathrm{P}]\right.$ and $\left[\mathrm{P}_{0}\right]$ are the concentrations of peroxide at time $t$ and time 0 ), the plots were on a straight line at least until 50-\% decomposition. Haas determined the rates of decomposition of benzoyl peroxide in polystyrene films by iodometry, ${ }^{3}$ and then by infrared spectrophotometry, ${ }^{4}$ and the results of the two methods were in fair agreement. The rates of decomposition of many peroxides yielding some acids and esters as products were determined by infrared spectrophotometry. ${ }^{5}$

The products of the decomposition were analyzed as follows. The polystyrene film was dissolved in benzene. When the benzene solution was poured into methanol, polystyrene precipitated. This procedure was repeated. The reprecipitated polystyrene contained some cinnamoyloxy group as a substituent. The polymer 
was redissolved in benzene, and the solution was evaporated on a plate. The amount of cinnamoyloxy group in the polystyrene film was determined by the comparison of the infrared spectrum of the film with that of a polystyrene film of the same thickness containing a known amount of phenyl cinnamate.

The benzene-methanol solution containing nonpolymeric products were evaporated to dryness. The yellow solids were dissolved in carbon tetrachloride, and the acid products were extracted with a 2-\% sodium hydrogen carbonate solution. The sodium hydrogen carbonate solution was acidified, and the acidic products were extracted with ether. The evaporation of the ethereal solution yielded white crystals, which were identified as cinnamic acid on the basis of its melting point $\left(132-134^{\circ} \mathrm{C}\right.$; lit. $\left.^{6} 135-136^{\circ} \mathrm{C}\right)$ and infrared spectrum $(\mathrm{C}=\mathrm{O}$ absorption at 1690 $\mathrm{cm}^{-1}$; its infrared spectrum is superimposable with that of an authentic sample).

The carbon tetrachloride solution containing nonacidic products was evaporated to dryness, yielding yellowish solids. Its infrared spectrum had a strong absorption at $1735 \mathrm{~cm}^{-1}$, indicating it to be an ester. It was not possible to purify this ester further. The $\mathrm{CH}$ analyses (C, 81.0, $\mathrm{H}$, 5.51) roughly corresponded with styryl cinnamate $\left(\mathrm{C}_{17} \mathrm{H}_{14} \mathrm{O}_{2}, \mathrm{C}, 81.6, \mathrm{H}, 5.60\right)$. Styryl cinnamate is an enol ester, and has not been reported in the literature. Since there is no convenient way for preparing this compound, the identification of the ester with an authentic sample was not made.

Decomposition of Benzoyl Peroxide in Polystyrene

Benzoyl peroxide and polystyrene were dissolved in benzene, and films were prepared and heated in a manner similar to that described above for the case of cinnamoyl peroxide.

\section{Decomposition on Benzoyl Peroxide in Biphenyl or Phenanthrene}

Benzoyl peroxide and biphenyl (or phenanthrene) were dissolved in chloroform, and the solvent was removed under reduced pressure. The solid mixture obtained appeared to be a homogeneous mixture. It was further ground and mixed well in a mortar, and $0.100-\mathrm{g}$ portions were placed in glass ampoules. The ampoules were placed in a constant temperature bath and removed at suitable intervals. The samples were dissolved in chloroform, and their infrared absorptions were determined against a chloroform solution containing biphenyl (or phenanthrene). The absorption at $995 \mathrm{~cm}^{-1}$ was used since those at 1760 and $1785 \mathrm{~cm}^{-1}$ were mixed with those of the products. Good firstorder rate plots were obtained.

\section{Products of Decomposition of Benzoyl Peroxide in Phenanthrene}

Benzoyl peroxide $(2.00 \mathrm{~g})$ and phenanthrene $(24.7 \mathrm{~g})$ were dissolved in chloroform, and the solvent was removed under reduced pressure. The solid mixture was ground in a mortar, and then decomposed at $60^{\circ} \mathrm{C}$ for 11 half-lives $(10 \mathrm{hr})$. The mixture was then dissolved in a small amount of chloroform, and phenanthrene was precipitated by the addition of methanol. This procedure was repeated and most of the phenanthrene successfully removed. The brown oily residue obtained was dissolved in chloroform and benzoic acid extracted with a 5-\% $\mathrm{NaHCO}_{3}$ aqueous solution; $0.724 \mathrm{~g}(5.92 \mathrm{mmol})$ of benzoic acid was obtained (mp $120-122^{\circ} \mathrm{C}$; lit. ${ }^{7} 122^{\circ} \mathrm{C}$; the main IR absorption, $1690 \mathrm{~cm}^{-1}$; its IR spectrum was identical with that of an authentic sample of benzoic acid). Then the residue (4.495 g) was subjected to a column-chromatographic separation on alumina. The first fraction was phenanthrene. The second substance eluted was a yellow solid $(0.491 \mathrm{~g})$ which starts melting at $166^{\circ} \mathrm{C}$ and completely melts at $220^{\circ} \mathrm{C}$. It is an ester absorbing at $1710 \mathrm{~cm}^{-1}$ with a shoulder at $1675 \mathrm{~cm}^{-1}$, but its melting point is higher than those of 9-benzoyloxyphenanthrene $\left(96.7^{\circ} \mathrm{C}\right)$ or phenyl benzoate $\left(70^{\circ} \mathrm{C}\right)$. It is probably a mixture of phenanthrenes benzoyloxylated at various positions. The third fraction eluted was a brown oil $(0.559 \mathrm{~g})$, which appeared to be a mixture of esters, absorbing at $1710-1730 \mathrm{~cm}^{-1}$ with a shoulder at $1675 \mathrm{~cm}^{-1}$. Its IR spectrum suggested that its main component is phenyl benzoate.

\section{RESULTS AND DISCUSSION}

The rates of decomposition of cinnamoyl peroxide in polystyrene film was of the first order, and the rate constants obtained are shown in Table I. 
Table I. Rates of decomposition of cinnamoyl peroxide in solid polystyrene film at $80^{\circ} \mathrm{C}$

\begin{tabular}{lll}
\hline Mol peroxide/mol styrene unit & $1 / 200$ & $1 / 50$ \\
Film thickness, mm & 0.04 & 0.04 \\
$k_{1}, \mathrm{sec}^{-1}$ & $2.9 \times 10^{-5}$ & $3.0 \times 10^{-5}$
\end{tabular}

Table II. Products of decomposition of cinnamoyl peroxide in polystyrene at $80^{\circ} \mathrm{C}$

\begin{tabular}{|c|c|c|}
\hline Products & Mol & $\begin{array}{l}\text { Mol } / \mathrm{mol} \\
\text { Peroxide }\end{array}$ \\
\hline $\mathrm{PhCH}=\mathrm{CH}-\mathrm{COOH}$ & $\begin{array}{l}3.86 \times 10^{-4} \\
7.52 \times 10^{-5}\end{array}$ & $\begin{array}{ll}4 & 0.59 \\
5 & 0.11\end{array}$ \\
\hline
\end{tabular}

Percent accounted for; $(0.59+0.11) / 2+0.38=0.73$

\section{a Incomplete identification.}

Cinnamoyl peroxide used, $6.58 \times 10^{-4} \mathrm{~mol} ; \mathrm{mol}$ peroxide/mol styrene unit, 1/10; film thickness, 0.04 $\mathrm{mm}$; heated at $80^{\circ} \mathrm{C}$ for $40 \mathrm{hr}$.

Since the rate of decomposition of cinnamoyl peroxide in organic solvents has not been reported in the literature, it was not possible to compare the rate in solid with that in a solution. Haas determined the rate of decomposition of benzoyl peroxide in polystyrene, and found that it was smaller than that in benzene. ${ }^{3}$

The products of the decomposition of cinnamoyl peroxide in polystyrene are summarized in Table II.

As Table II shows, cinnamoyloxy groups are introduced into polystyrene, but not in a good yield. Greater portions of the peroxide are converted to cinnamic acid and an ester.

Styryl cinnamate is not reported in the literature, and therefore the structural assignment of the ester obtained to styryl cinnamate is tentative. Simamura, Tokumaru, and $\mathrm{Yui}^{8}$ studied the decomposition of cinnamoyl peroxide in carbon tetrachloride, and found that the products were $81 \%$ trans- and $19 \%$ cis- $\beta$-chlorostyrene. It is worth noting that in our experiments a considerable amount of esters was found, whereas in their experiments in solutions cinnamoyloxy radicals were decarboxylated completely and the only products isolated were chlorostyrenes. The geminate pair of cinnamoyloxy radicals produced in the solid phase can remain close to each other for a longer period than in the case of a solution. It is quite probable that in the solid phase one of the cinnamoyloxy radicals attacks the reactive $\mathrm{C}=\mathrm{C}$ bond of the other cinnamoyloxy radical, forming styryl cinnamate and carbon dioxide.

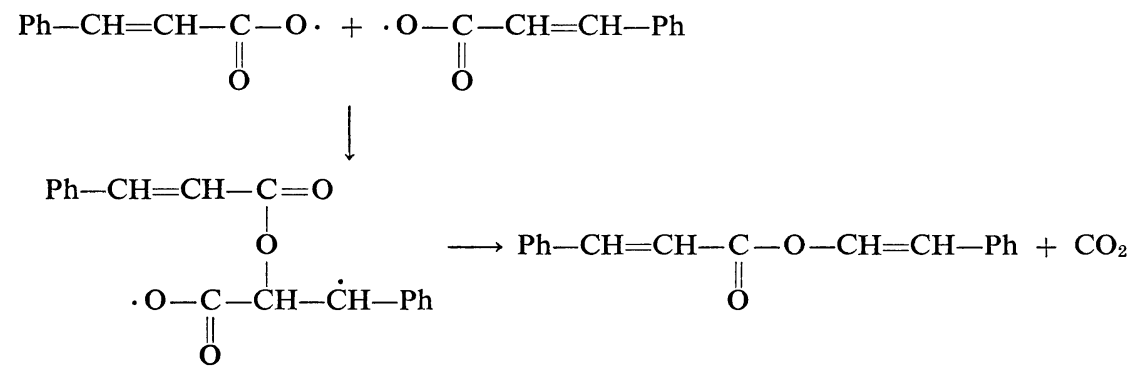

In solutions, diffusion is quite rapid, and it is likely that the cinnamoyloxy radicals diffuse away, decarboxylate and react with solvents.

Undoubtedly, a part of the cinnamoyloxy radicals are decarboxylated, forming styryl radicals and carbon dioxide moelcules. The styryl radicals may either attack polystyrene to form $\mathrm{Ph}-\mathrm{CH}=\mathrm{CH}-\mathrm{C}_{6} \mathrm{H}_{4}-\stackrel{!}{\mathrm{C}} \mathrm{H}-\mathrm{CH}_{2}-$ or abstract hydrogen atoms to form styrene. However, the work of Haas ${ }^{3,4}$ and the results of this investigation show that the decarboxylation of both benzoyl peroxide and cinnamoyl peroxide are much less extensive in the solid-phase decomposition than in the liquid-phase equivalent.

As shown in Table II, the yield of cinnamic acid is greater than that of cinnamoyloxylated polystyrene. This could be explained by assuming that part of the cinnamoyloxy radicals abstract hydrogen atoms from polystyrene.

The results of the decomposition of cinnamoyl peroxide in polystyrene may be summarized as follows. 
H. Minato, C. Kato, and I. Mori<smiles>CCC(C)c1ccc(-c2ccccc2)cc1OC(=O)C=CC(=O)OC(=O)C=Cc1ccccc1</smiles>

Table III. Products of decomposition of benzoyl peroxide in polystyrene

\begin{tabular}{ccccccc}
\hline Mol BPO/Mol St unit & $\begin{array}{c}\text { Film } \\
\text { thickness, } \\
\mathrm{mm}\end{array}$ & $\begin{array}{c}\text { Temp, } \\
{ }^{\circ} \mathrm{C}\end{array}$ & $\begin{array}{c}\text { Time, } \\
\mathrm{hr}\end{array}$ & $\mathrm{PhCOOH}$ & $\mathrm{PhCOOPh}$ & $\begin{array}{c}\text { Phoducts, } \mathrm{mol} / \mathrm{mol} \mathrm{BPO} \\
\text { PhCOOC }\end{array} \mathrm{H}_{4} \mathrm{CH}-\mathrm{CH}_{2}-$ \\
\hline $1 / 52^{\mathrm{a}}$ & 0.127 & 73 & 263 & 0.369 & 0.237 & 0.474 \\
$1 / 52^{\mathrm{a}}$ & 0.27 & 90 & 48 & 0.352 & 0.263 & 0.474 \\
$1 / 22$ & 0.0178 & 100 & 5.5 & 0 & 0 & 0.470 \\
\hline
\end{tabular}

a The work of Haas. ${ }^{3}$

Haas reported that $0.474 \mathrm{~mol}$ of benzoyloxy group was attached to polystyrene per mol of benzoyl peroxide decomposed in a polystyrene film. ${ }^{3}$ This value is much larger than that found with cinnamoyl peroxide $(0.11 \mathrm{~mol})$. Therefore, the decomposition of benzoyl peroxide in polystyrene was checked. In Table III, the results are compared with those of Haas.

The film was thinner, the peroxide concentration was higher, and the temperature was higher than the experiments done by Haas, but the

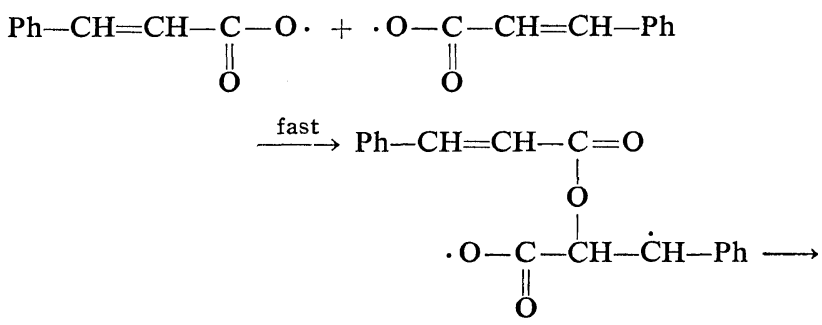<smiles>C#COC(=O)C(=O)OC=Cc1ccccc1</smiles>

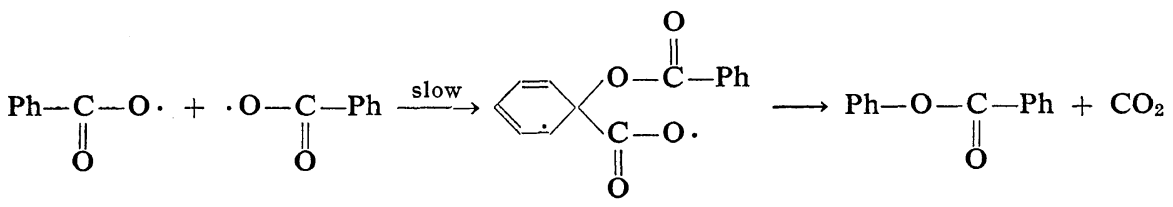


In our experiment with benzoyl peroxide, neither benzoic acid nor phenyl benzoate was found in the polystyrene film. Since our films were much thinner than those used by Haas, it was probable that these compounds evaporated as they were formed. In order to check this the following control experiment was carried out. When a polystyrene film containing comparable amounts of these two compounds was prepared and heated for $5.5 \mathrm{hr}$ at $100^{\circ} \mathrm{C}$, it was found that both compounds completely disappeared from the film.

It is worth noting that the rate of decomposition of cinnamoyl peroxide in polystyrene at $80^{\circ} \mathrm{C}$ is very small $\left(k_{1}=2.9 \times 10^{-5} \mathrm{sec}^{-1}\right)$ and the rate of decomposition of benzoyl peroxide in polystyrene at $80^{\circ} \mathrm{C}$ is much smaller $\left(k_{1}=\right.$ $\left.1.11 \times 10^{-5} \mathrm{sec}^{-1}\right)^{3}$ than that in a benzene solution $\left(k_{1}=3.28 \times 10^{-5} \mathrm{sec}^{-1}\right) .^{9} \quad$ The smaller rates can be ascribed to the recombination of the geminate pair of the acyloxy radicals produced in the cage. The rate of recombination is found to increase with the viscosity of the media,${ }^{10}$ and it is possible that a certain portion of the acyloxy radicals recombine in solid polystyrene.

Imoto et al., found that the benzoyl peroxide decomposes very readily when electron-donating $N, N$-dimethylaniline is present in the solution. ${ }^{11}$ The enhanced rate of decomposition has been ascribed to the electron transfer from the dimethylaniline to the peroxide. When peroxide molecules are surrounded by solid electrondonating molecules, it is possible that decomposition is accelerated. Imoto and Takemoto recently discussed the relationship between electron transfer and ionization potential of radicals. ${ }^{12}$

It seems to be of interest to examine the decomposition of peroxides in some solid arenes of low ionization potentials. The ionization potentials of some aromatics are the following ${ }^{13}$ (in $\mathrm{eV}$ ); benzene, 9.43; isopropylbenzene, 9.13; biphenyl, 8.30; phenanthrene, 8.03; aniline, 7.70; anthracene, 7.37 .
Table IV. Rates of decomposition of benzoyl peroxide in various media

\begin{tabular}{lcc}
\hline \multicolumn{1}{c}{ Molar ratio } & $\begin{array}{c}\text { Temp, } \\
{ }^{\circ} \mathrm{C}\end{array}$ & $\begin{array}{c}10^{5} \times k_{1}, \\
\mathrm{sec}^{-1}\end{array}$ \\
\hline $1.9 \mathrm{~mol} / 100 \mathrm{~mol} \mathrm{Biphenyl}$ & 80.0 & 1.5 \\
$1.9 \mathrm{~mol} / 100 \mathrm{~mol}$ Phenanthrene & 80.0 & 94.6 \\
$1.9 \mathrm{~mol} / 100 \mathrm{~mol} \mathrm{Phenanthrene}$ & 70.0 & 31.3 \\
$4.9 \mathrm{~mol} / 100 \mathrm{~mol} \mathrm{Phenanthrene}$ & 70.0 & 29.5 \\
$4.9 \mathrm{~mol} / 100 \mathrm{~mol}$ Phenanthrene & 60.0 & 22.3 \\
$2.0 \mathrm{~mol} /$ Polystyrene (100 mol St unit) & 80.0 & $1.11^{\mathrm{a}}$
\end{tabular}

a The work of Haas. ${ }^{3}$

In order to determine the accelerating effects of aromatics, the decomposition of benzoyl peroxide in solid biphenyl was examined. Benzoyl peroxide and biphenyl (molar ratio, $1: 19$ ) were dissolved in chloroform, and the solution was evaporated under reduced pressure. The solid powder was ground on a mortar, and then samples were allowed to decompose at $80^{\circ} \mathrm{C}$. The rate $\left(k_{1}=1.5 \times 10^{-5} \mathrm{sec}^{-1}\right)$ was not much different from those in benzene or polystyrene.

When a chloroform solution containing benzoyl peroxide and anthracene was evaporated, anthracene alone crystallized out because of the great difference in solubility.

When a chloroform solution of benzoyl peroxide and phenanthrene was evaporated, a homogeneous solid mixture was obtained, which was further ground and well mixed on a mortar. The solid samples were allowed to decompose and the rates were determined. The results are shown in Table IV.

It is of great interest that the rate of decomposition of benzoyl peroxide in solid biphenyl is about the same as that in polystyrene, whereas the rate in solid phenanthrene is far greater. The ionization potentials of biphenyl and phenanthrene are 8.30 and $8.03 \mathrm{eV}$, respectively. It is possible that electron-donating phenanthrene transfers an electron to the peroxidic bond, inducing the decomposition of the peroxide.

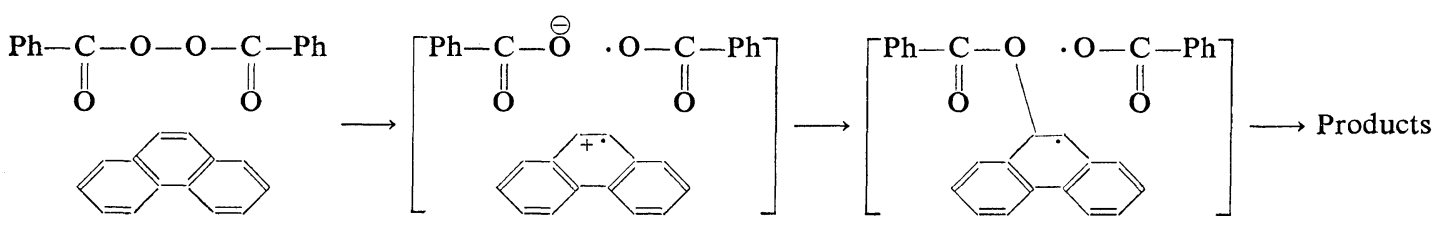


Greene, Adam and Cantrill found that $m, m^{\prime}$ dibromobenzoyl peroxide reacted with $p, p^{\prime}$ dimethoxy-trans-stilbene, forming dihydroanisoin bis- $m$-bromobenzoate. ${ }^{14}$ They suggested a fourcentered mechanism, but an oxygen-18 study showed that the reaction is not a concerted reaction, but a stepwise one. ${ }^{15}$ It is possible that their reaction proceeds via electron transfer in a similar manner.

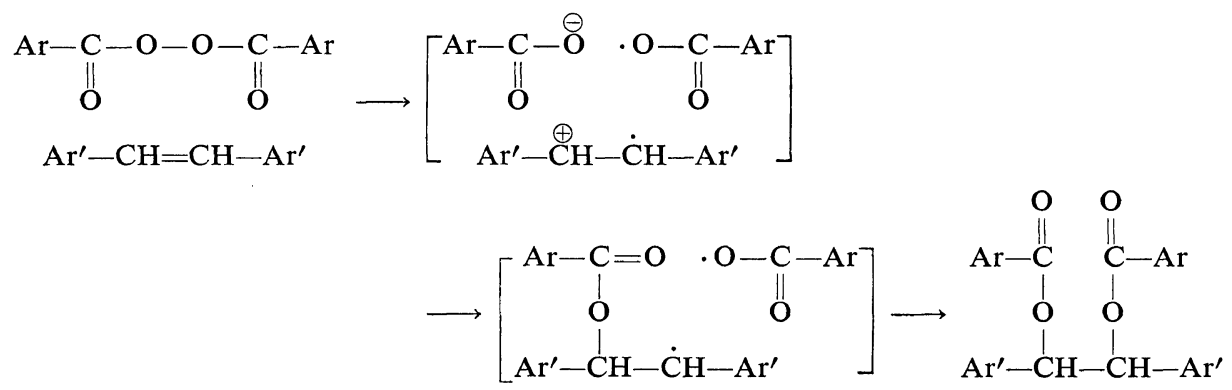

The induced decomposition of benzoyl peroxide by triphenylmethyl radical ${ }^{16}$ can be explained by a similar electron-transfer mechanism. The ionization potential of triphenylmethyl radical is $7.26 \mathrm{eV}$.

The products of the decomposition of benzoyl peroxide $(2.0 \mathrm{~g})$ in solid phenanthrene $(24.7 \mathrm{~g})$ were complex; the products were benzoic acid $(0.72 \mathrm{~mol} / \mathrm{mol} \mathrm{BPO})$, a brown oil (mainly $\mathrm{PhCO}_{2} \mathrm{Ph} ; 0.34 \mathrm{~mol} / \mathrm{mol} \mathrm{BPO}$ ) and a solid ester (mp $166-220^{\circ} \mathrm{C}$; a mixture of benzoyloxylated phenanthrenes, $0.491 \mathrm{~g}$ ).

The results of this investigation show that the decompositions of peroxides in solid could be very different from the decompositions in liquid. The fact that $0.47 \mathrm{~mol}$ benzoyloxy radical (per mol of BPO decomposed) is efficiently attached to polystyrene nuclei is in quite a contrast with the low yield of phenyl benzoate $(0.01-0.02 \mathrm{~mol} / \mathrm{mol} \mathrm{BPO})$ in the decomposition of BPO in benzene. ${ }^{17}$ The yield of cinnamoyloxylation of polystyrene was lower $(0.11 \mathrm{~mol} / \mathrm{mol}$ peroxide), but even this value is much greater than the yield in the benzoyloxylation of benzene mentioned above.

In the decomposition of peroxide in polystyrene above, its second-order transition temperature (about $82^{\circ} \mathrm{C}$ ) and the content of polystyrene of low molecular weight probably have some influence on the decomposition of peroxides.

Roitt and Waters studied the decomposition of BPO in a mixture of chlorobenzene and polycyclic aromatics. ${ }^{18}$ They found that the decomposition of BPO was not affected at all by the presence of phenanthrene; the products were the same as those in chlorobenzene alone and no phenanthrene derivatives were isolated by chromatography. This contrasts with the results of this investigation. Apparently phenanthrene can affect the decomposition of BPO only in the solid phase, and not in liquid phase. Roitt and Waters found some aromatics did attack BPO and considerable yields of benzoyloxylated aromatics were found; the relative order of reactivities was benz[i]pyrene $>$ anthracene, benz $[\mathrm{a}]$ anthracene $>\operatorname{dibenz}[\mathrm{a}, \mathrm{h}]$ anthracene $>$ chrysene, phenanthrene.

An attractive hypothesis suggested from their results and our results is that the arenes with fairly low ionization potential can affect the decomposition of peroxides only in solid phase, whereas the arenes with very low ionization potentials can affect the decomposition in both solid and liquid phases.

Therefore, if poly(vinylphenanthrene) or poly(vinylchrysene) is prepared and benzoyl peroxide or cinnamoyl peroxide is mixed in the solid phase, it seems possible that efficient benzoyloxylation or cinnamoyloxylation takes place at temperatures lower than those for usual spontaneous decompositions. If diperoxides are used, cross-linking by diester formation is expected.

\section{REFERENCES}

1. H. Minato and R. Hisada, J. Polym. Sci., Part $A-1,7,735$ (1969). 
2. N. G. Sana, U. S. Nandi, and S. R. Palit, $J$. Chem. Soc., 427 (1956).

3. H. C. Haas, J. Polym. Sci., 39, 493 (1959).

4. H. C. Haas, ibid., 55, 33 (1961).

5. P. D. Bartlett and R. R. Hiatt, J. Amer. Chem. Soc., 80, 1398 (1958).

6. "Kagaku Binran (Chemistry Handbook)," Maruzen, Tokyo, 1966, p 223.

7. ibid., p 181.

8. O. Simamura, K. Tokumaru, and H. Yui, Tetrahedron Lett., 5141 (1966).

9. K. Nozaki and P. D. Bartlett, J. Amer. Chem. Soc., 68, 1686 (1946).

10. J. C. Martin and H. Hargis, ibid., 91, 5399 (1969).

11. M. Imoto and S. Choe, J. Polym. Sci., 15, 485
(1955); M. Imoto, T. Otsu, and K. Kimura, ibid., 15, 475 (1955).

12. M. Imoto and K. Takemoto, Nippon Kagaku Kaishi (J. Chem. Soc. Japan), 177 (1975).

13. "Kagaku Binran (Chemistry Handbook)," Maruzen, Tokyo, 1966, p 1127.

14. F. D. Greene, W. Adam, and J. E. Cantrill, J. Amer. Chem. Soc., 83, 3461 (1961).

15. M. Kobayashi, H. Minato, and Y. Ogi, Bull. Chem. Soc. Japan, 43, 1158 (1970).

16. G. S. Hammond, J. T. Rudesill, and F. J. Modic, J. Amer. Chem. Soc., 73, 3929 (1951).

17. G. B. Gill and G. H. Williams, J. Chem. Soc., 995 (1965).

18. I. M. Roitt and W. A. Waters, ibid., 2695 (1952). 